\title{
Patterns of Variation of Herbivore Assemblages at Nairobi National Park, Kenya, 1990-2008
}

\author{
Alfred O. Owino ${ }^{1}$, Moses Lekishon Kenana ${ }^{2}$, Paul Webala ${ }^{3}$, Samuel Andanje ${ }^{1}$, Patrick O. Omondi ${ }^{1}$ \\ ${ }^{1}$ Biodiversity Research \& Monitoring Division, Kenya Wildlife Service, Nairobi, Kenya; ${ }^{2}$ Nairobi National Park, Nairobi, Kenya; \\ ${ }^{3}$ Kenya Wildlife Service Training Institute, Naivasha, Kenya. \\ Email: Alfred@kws.go.ke
}

Received April 5 ${ }^{\text {th }}, 2011$; revised May 24 $4^{\text {th }}, 2011$; accepted July $6^{\text {th }}, 2011$.

\begin{abstract}
Wildlife, especially mammals populations dynamics in many conservation areas are influenced by ecosystem processes and increasingly by climate change. Generally, cyclic population dynamics is relatively common among small mammals, especially in high latitudes but is not yet established among many African savanna ungulates. Habitat fragmentation and loss propagated by anthropogenic activities are responsible for the decline in populations of many wildlife species leading to the confinement many wildlife species particularly herbivores within parks and reserves as a conservation measure. We assessed the patterns of variation in abundance of eight herbivore species (African Buffalo, Eland, Burchell's Zebra, Wildebeest, Giraffe, Grant's Gazelle, Thomson's Gazelle and Impala) at Kenya's Nairobi National Park using population counts data over the period 1990-2008. Overall, the eight herbivores abundances declined within the Park with significant declines in Wildebeest $\left(R^{2}=0.54\right)$, Grant's Gazelle $\left(R^{2}=0.72\right)$ and Impala $\left(R^{2}\right.$ $=0.80)$. Seasonality had effects on herbivore numbers and assemblages at the Park with the numbers of individual species increasing within the Park during dry seasons compared to wet seasons ( $t$-test, $t=4.45, p=0.03$ ). Land use changes and urban development, especially in the dispersal areas and the accompanying effects of climate change of reduced rainfall and longer periods of drought had significant negative impacts on herbivore assemblages at the Park. We discuss the significance of the population fluctuations of the eight species at the Park, the potential impacts of the changes on Park ecosystem processes and the expected long-term population dynamics of the species if the conditions remain as witnessed over the past two decades.
\end{abstract}

Keywords: Nairobi National Park, Herbivores, Habitat Fragmentation, Climate Change

\section{Introduction}

The monitoring of populations of wildlife species is an established management practice [1]. This implies site monitoring so that changes in the populations can be assessed against a standard level [2]. To define such standards, natural variability must first be examined through surveillance-a repeated set of surveys conducted in a standardized manner over longer periods. Wildlife population trend analyses obtained through regular long-term censuses datasets have been of continual interest to ecologists and wildlife management authorities [1]. Extensive research, especially on small mammal in the northern latitudes has implicated a predator-prey interaction as the most pervasive cause of population cycles [3]. In the search for general patterns of wildlife population trends, the influence of the past is largely ignored, despite substantial evidence of historical constraints that may range from major events to short-term disturbances [4]. However, there has been a general appreciation of the influence of rainfall, food availability and periodicity in the dynamics, especially of large herbivore populations [5]. In addition, there has been a growing interest on the effects of anthropogenic activities, invasive/alien species, and most recently climate change as key drivers of wildlife population trends, especially in the tropics [1,6-9].

In Africa, populations of many wildlife species have declined substantially inside and outside the protected areas [1,6,10-13]. Contributory causes include recurrent droughts $[6,14,15]$, land-use changes $[6,16]$, growing human settlements [17], illicit hunting [18] and livestock incursions into protected areas [6]. In East Africa wildlife population dynamics within many conservation areas are influenced by many factors including trophic interactions with resources [19], autocorrelated exogenous factors [20], climate change effects [5] and land use changes/ 
reduction in ecological ranges [7,21].

Given that the delineation of many conservation areas, especially in East Africa did not align conservation areas with ecosystem boundaries, many conservation areas do not encompass whole ecosystems [22]. Consequently, variations in wildlife numbers, especially herbivores observed within confines of parks and reserves are common because their natural ranges do or do not extend well beyond the boundaries of the protected areas particularly for the for the fenced protected areas. For example, migrations of wildebeest in the Mara-Serengeti ecosystem occur between a conservation area and adjoining dispersal areas, clearly showing that the Mara-Serengeti ecosystem are not adequate for the protection and viability, especially for the migratory wildebeest [23]. For the fenced protected areas such as Lake Nakuru National Park, herbivores are confined within smaller areas with limited access to the surrounding areas. In parks such as Amboseli in southern Kenya, the land use changes in the surrounding areas are increasingly confining African Elephant Loxodonta africana within the park leading to significant habitat alterations because of herbivory intensity. Because wildlife in nature are neither distributed uniformly or at random, but instead form spatial patterns [24], the type of spatial arrangement present may suggest certain interactions within and between species, such as competition, predation, and reproduction [25]. On the other hand, certain spatial patterns may also rule out specific ecological theories previously thought to be true [26].

Nairobi National Park is a peri-urban protected area that represents a small portion of the larger NairobiAthi Kapiti ecosystem in southern Kenya. It has in the past been operationally defined by the range of the migratory wildlife species such as wildebeest as exemplified in the Mara-Serengeti ecosystem [8,27-29]. The Park currently experiences serious anthropogenic effects and the impacts of expansion of Nairobi City, and has in recent times become increasingly susceptible to a multitude of external pressures likely of influence wildlife population dynamics. Given the susceptibility of the Park to influences from external pressures, Kenya Wildlife Service - the wildlife management authority in Kenya has been conducting regular and systematic wildlife population counts in the Park. This is especially important because the Park is one of the remaining major concentration areas for plains game species in southern Kenya, and the knowledge of patterns of variations in the numbers of common wildlife species is critical for conservation and management decisions.

In this paper, we present results from long term wildlife population monitoring data (1990-2008) at Nairobi National Park. We use index numbers of wildlife popula- tions to investigate patterns of variations of eight common herbivore species recorded within the Park, and assess the seasonal variability across wet and dry seasons. We discuss the relationships of the population dynamics with the ecological characteristics of the Park, and the expected future changes in the populations if the conditions witnessed in the past two decades persist.

\section{Study Area and Methods}

\subsection{Study Area}

Nairobi National Park $\left(01^{\circ} 17^{\prime} \mathrm{S}, 36^{\circ} 49^{\prime} \mathrm{E}\right)$ is an area of natural landscape at grassland-forest boundary, only 7 $\mathrm{km}$ from the centre of Kenya's capital city, Nairobi [30]. The Park was gazetted in 1947, and covers an area of about $117 \mathrm{~km}^{2}$ (Figure 1). Various habitat types includeing open rolling grass plains, riverine woodlands, valley thicket and bush, man-made dams and ponds, rocky gorges and upland dry forests occur within the Park [31]. It is fenced along three sides, where it is adjacent to urban housing, industry, roads and airports. Ecologically, the Park is intimately linked to Kitengela and Athi-Kipiti plains which adjoin it to the south, forming a single ecological unit [32]. Being close to Nairobi City, and with a variety of wildlife species, it is a popular destination for tourists, but faces obvious additional problems from the expanding urban area and human population growth

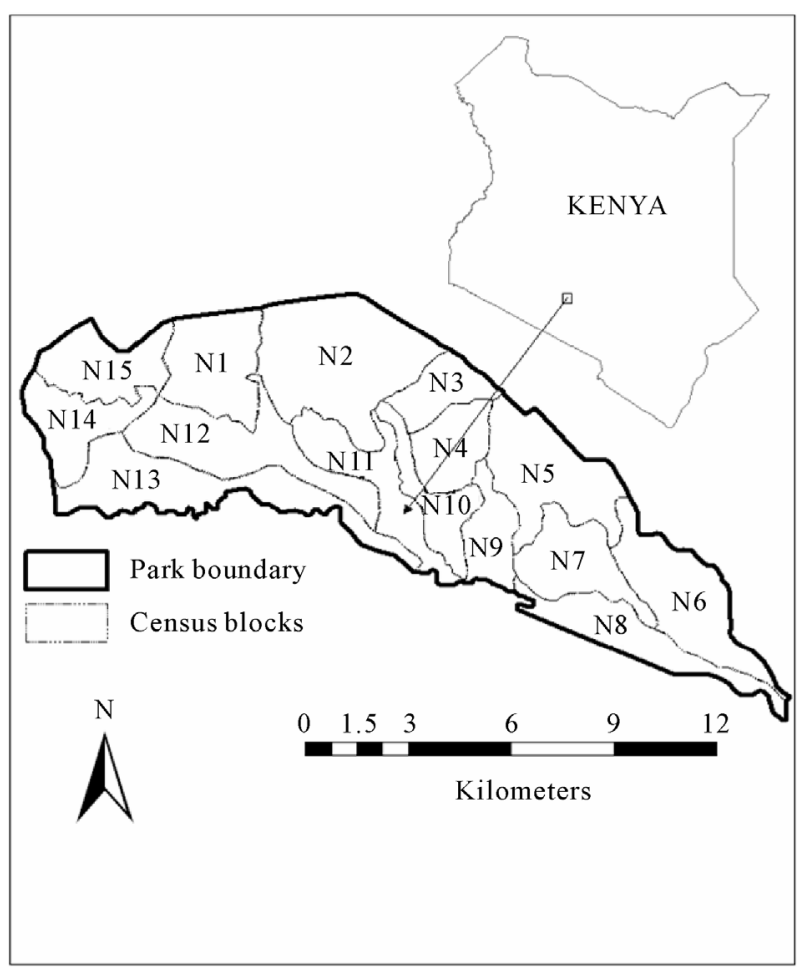

Figure 1. Nairobi National Park and locations of the census blocks. 
around it [33]. Despite all these challenges, it still serves as a dry season concentration area for major wildlife species particularly Wildebeest Connochaetes taurinus, Burchell's Zebra Equus burchelli and Eland Taurotragus oryx that make up over $50 \%$ of the total wildlife biomass of the park [32]. During wet seasons, most of these major plains game species disperse to the south outside the protected area boundary where they spend significant time of their annual seasonal cycles on private or communal lands. However, the migratory movement of wildlife has increasingly become constrained by sprawling settlements within the dispersal area.

\subsection{Animal Counts and Data Analysis}

Regular wildlife counts were conducted in the months of February, April, June, August, October and December coinciding with the wet and dry seasons as part of the on-going long-term wildlife population monitoring by the wildlife management authority - the Kenya Wildlife Service. Fifteen (15) blocks (Figure 1) were assigned to teams of volunteers using vehicles on specified roads within the blocks. All plains game species on either side of the road up to an estimated distance of $250 \mathrm{~m}$ on both sides were counted using binoculars and numbers recorded in designed datasheets over a single morning from 0600 hrs to mid-day using a combination of the Distance and the Strip census techniques [34]. The distance to which animal or groups of animals were sighted was estimated and recorded at right angles to the vehicle. This estimation of distance allowed for application of species correction factors [34]. The count data for each plains game wildlife species recorded were summarized for each block and for the entire Park over the census period, 1990-2008. In this paper, we focused on the eight common herbivores counted over the period, i.e. African Buffalo Syncerus caffer; Eland Taurotragus oryx; Burchell's Zebra Equus quagga burchelli; Wildebeest Connochaetus taurinus; Giraffe Giraffa camelopardalis tippelkirchi; Grant's Gazelle Gazella granti; Thomson's Gazellle Gazella rufifrons and Impala Aepyceros melampus. When examining overall variability in numbers of these species, we analyzed data for each month separately and combined per year and only significant trends shown [35]. The logarithmic indices of relative abundance for each species were computed as follows:

Population index $(\gamma)=\log _{10}\left((\lambda / \delta)^{*} 100\right) / 2$

where $(\lambda)=$ Observed abundance - from each annual count; $(\delta)$ = Mean abundance of count for each species. The abundance for one year $(\lambda)$ is scaled as a percentage of mean abundance $(\delta$ ) over the number of annual counts (including the year in question, 1990-2008). The log (we have used base ten) of this is taken to avoid inconsisten- cies caused by different scale factors [36]; this is then halved so that the mean abundance corresponds to an index of 1.0. The sample variances of these indices were then taken as a measure of relative variation for each species. Pearson correlation co-efficient were computed from the indices to determine if patterns of variation were related. The population fluctuations across seasons and years was established using autocorrelation autocorrelelograms based on approximate 95\% tolerance limits under the assumption that the underlying autocorrelations is zero at all lags [5,37-39], and autocorrelations used to document the existence of patterns of abundance for the eight herbivores.

\section{Results}

\subsection{Overall Variations in Abundances}

The annual abundance indices for the eight common plains game counted at Nairobi National Park are shown in Table 1. Wildebeest (1788), Zebra (1310) and Impala (420) had the highest mean abundances over the period 1990-2008. Giraffe (81) and Grant's Gazelle (89) had the lowest records. Overall, wildebeest was the most variable over the period (variance $=0.19$ ). Generally higher records for all plains game species were made in the periods between 1990 and 2000 with numbers of all the species showing consistent declines thereafter. The overall pattern of abundance showed that the numbers of Wildebeest $\left(R^{2}=0.54, P=0.01\right)$, Grant's Gazelle $\left(R^{2}=0.72\right.$, $P=0.002)$ and Impala $\left(R^{2}=0.80, P=0.0001\right)$ declined significantly (Figures 2(a)-(c)). Other species showed annual fluctuations of different strengths but these were not significant although the general pattern was of a decline.

\subsection{Seasonal and Annual Variations}

The eight species showed seasonal variations of different strengths across the census months of February, April, June, August, October and December over the two decades at the Park coinciding with the wet seasons (i.e. April, October and December) and dry seasons (February, June, August). A pair-wise comparison of overall annual abundance pooled by seasons showed significant difference in numbers of the eight species within the Park ( $t=4.45, P$ $=0.03, \mathrm{n}=57$ ) with a general pattern of lower numbers for all the eight during the wet season months of April and October within the Park. The pair-wise assessments of abundance for individual species during dry and wet seasons showed variations of different levels but most were not significant, except for Burchell's Zebra $(P=$ $0.04)$ and eland $(P=0.03)$. Giraffe were generally fewer in the Park during wet seasons but numbers increased during drier months although the increases were not sig- 
Table 1. Annual abundance indices of eight herbivore species at Nairobi National Park, 1990-2008.

\begin{tabular}{|c|c|c|c|c|c|c|c|c|}
\hline \multirow{2}{*}{ Year } & \multicolumn{8}{|c|}{ Herbivore species } \\
\hline & $\begin{array}{l}\text { African } \\
\text { Buffalo }\end{array}$ & Eland & $\begin{array}{c}\text { Burchell's } \\
\text { Zebra }\end{array}$ & Wildebeest & Giraffe & $\begin{array}{l}\text { Grant's } \\
\text { Gazelle }\end{array}$ & $\begin{array}{l}\text { Thomson's } \\
\text { Gazellle }\end{array}$ & Impala \\
\hline 1990 & 0.98 & 1.09 & 1.08 & 1.09 & 1.09 & 1.09 & 1.09 & 1.13 \\
\hline 1991 & 1.00 & 1.08 & 0.99 & 0.95 & 1.05 & 1.05 & 1.00 & 1.09 \\
\hline 1992 & 1.05 & 0.97 & 0.99 & 1.06 & 1.01 & 1.06 & 0.91 & 1.08 \\
\hline 1993 & 1.05 & 1.00 & 1.03 & 1.16 & 1.03 & 1.06 & 0.96 & 1.08 \\
\hline 1994 & 1.01 & 0.97 & 1.02 & 1.16 & 1.03 & 1.08 & 0.97 & 1.08 \\
\hline 1995 & 1.02 & 0.98 & 1.01 & 1.16 & 1.03 & 1.07 & 0.97 & 1.08 \\
\hline 1996 & 1.02 & 0.98 & 1.09 & 1.23 & 1.01 & 1.04 & 1.09 & 1.06 \\
\hline 1997 & 0.99 & 0.90 & 1.05 & 1.11 & 0.94 & 0.99 & 0.99 & 0.98 \\
\hline 1998 & 1.01 & 0.97 & 1.08 & 1.07 & 0.99 & 0.99 & 1.06 & 1.01 \\
\hline 1999 & 0.88 & 0.94 & 1.02 & 1.01 & 0.94 & 0.97 & 1.06 & 0.97 \\
\hline 2000 & 0.90 & 0.95 & 1.12 & 1.09 & 0.97 & 1.02 & 1.11 & 1.02 \\
\hline 2001 & 0.87 & 0.82 & 0.72 & 0.01 & 0.93 & 0.96 & 1.01 & 0.91 \\
\hline 2002 & 0.99 & 0.96 & 0.77 & 0.04 & 0.95 & 0.89 & 1.02 & 0.88 \\
\hline 2003 & 0.96 & 1.03 & 0.70 & 0.06 & 0.95 & 0.86 & 0.90 & 0.81 \\
\hline 2004 & 0.91 & 1.04 & 0.91 & 0.39 & 0.95 & 0.92 & 0.91 & 0.81 \\
\hline 2005 & 1.07 & 1.07 & 1.04 & 0.57 & 0.98 & 1.01 & 0.98 & 0.90 \\
\hline 2006 & 1.05 & 1.05 & 0.97 & 0.56 & 1.01 & 0.94 & 0.94 & 0.88 \\
\hline 2007 & 0.93 & 0.90 & 0.92 & 0.29 & 0.99 & 0.85 & 0.91 & 0.82 \\
\hline 2008 & 1.12 & 1.09 & 1.00 & 0.43 & 1.06 & 0.93 & 0.92 & 0.97 \\
\hline Mean of $(\delta)$ & 198 & 125 & 1310 & 1788 & 81 & 89 & 101 & 420 \\
\hline Variance of $(\gamma)$ & 0.005 & 0.005 & 0.014 & 0.192 & 0.002 & 0.006 & 0.005 & 0.011 \\
\hline
\end{tabular}

nificant. Autocorrelations (Figure 3(a)-(h)) of the counts with the previous year with half cycle periods showed different patterns for all the eight herbivores, with the wildebeest numbers showing least autocorrelations after the year 2000 .

\subsection{Correlations in Abundance of the Eight Herbivores}

There were substantial direct correlations in indices of abundance of the eight species over the period. Of the seventeen (17) direct correlations (with uncorrected $P<$ 0.05 ), seven were significant. Such correlations would in any case be expected to arise by chance in this set of 36 paired analyses. In particular, significant correlations were noted between numbers of zebra and wildebeest (Pearson, $R=0.71)$, Thomson's gazelle $(R=0.63)$ and impala $(R=0.62)$. Other significant correlations were noted in the numbers of Grant's gazelle and wildebeest ( $R=0.77)$, impala and Grant's gazelle $(R=0.93)$, giraffe and eland $(R=0.61)$. However, based on behavioral ecology of the species considered these correlations could have some ecological meanings. On the other hand, the spatial distribution patterns of zebra in the Park were particularly striking with records made in most census blocks, and their numbers were directly correlated with most plains game species in the Park.

\section{Discussion}

Given its spectacular diversity of wildlife and increasing human population, Kenya continues to experience significant challenges in wildlife conservation, and areas such as Masai Mara Reserve have witnessed significant declines in wildlife populations [7]. Our analysis of patterns of variation in numbers of eight common herbi- 


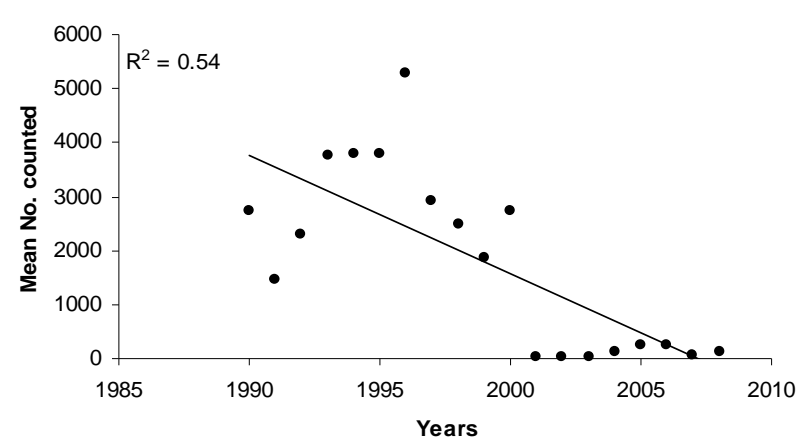

(a)

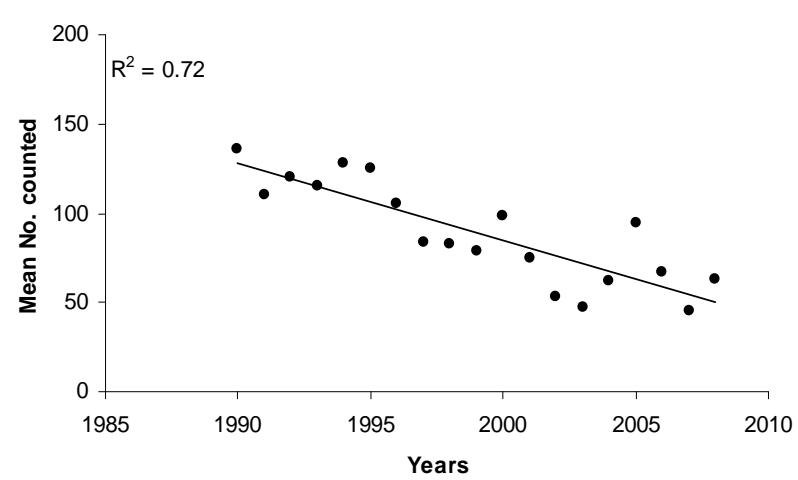

(b)

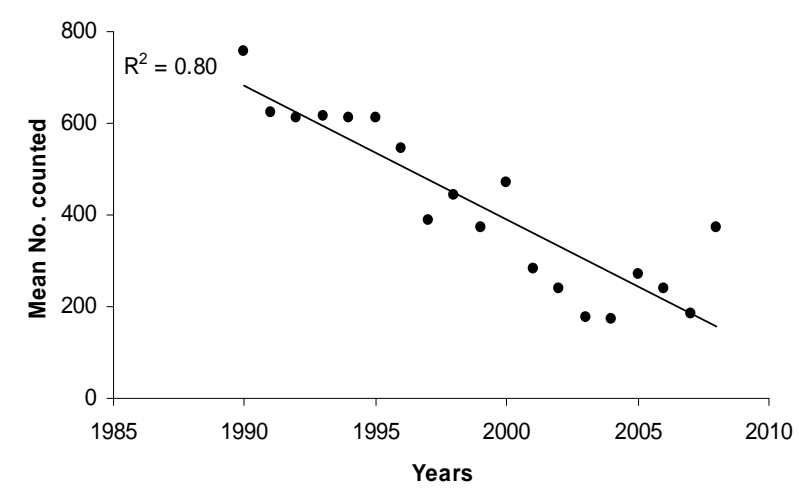

(c)

Figure 2. (a) Regression analysis of the numbers of wildebeest at Nairobi National Park, Kenya; (b) Regression analysis of the numbers of Grant's gazelle at Nairobi National Park, Kenya; (c) Regression analysis of the numbers of impala at Nairobi National Park, Kenya.

vores in the partially fenced Nairobi National Park suggests that many species of herbivores within the Park are experiencing declines of different levels depending on their ecology and habitat requirements. This is not particularly surprising given the anthropogenic pressures that the Park continues to experience. The dispersal areas for wildlife are increasingly encroached resulting in few dispersal areas. The wildlife species that find their ways out of the Park rarely return because of continued human encroachment and settlement in the dispersal area. Our field observations showed that in the long-term land use changes within the dispersal areas could have significant impacts on the future status of the Park as one of the remaining refuges for wildlife in southern Kenya. In addition, fluctuations in rainfall and increased forage competition from cattle within the dispersal area may further contribute to the decline for most species, especially in the Athi-Kipiti plains.

\subsection{Significance of Population Changes}

The eight species showed substantial variability in numbers at the Park over the period, which is unsurprising given their migratory patterns in and out of the Park through the southern sections. However, the overall decline in numbers shown by the species in the Park could act as an early warning on the need for urgent conservation actions for the long-term viability of the Park and the dispersal areas within the Athi-Kapiti areas as most plains game species are known to traverse this area and beyond feeding and calving [40]. The potential impacts of climate change resulting in temporal rainfall variability would further underpin the dynamics of wildlife habitat at the Park since there is a well established relationship between rainfall and primary production of grass in semi-arid tropics [5,14]. This coupled with the anthropogenic factors would further exacerbate the decline patterns for herbivores and other wildlife species [29,33, 41,42].

The increase in numbers of the plains game species within the Park during dry season indicated that the Park has still maintained its reputation as a concentration area for wildlife species, although the several man-made dams providing water for wildlife within the Park are increaseingly affected by prolonged seasons of drought leading to reduced water volumes. However, this pattern could be unpredictable as observed in other similar ecosystems in Kenya such as the Mara-Serengeti that has been characterized by alternating periods of predominantly dry years followed wet years lasting for long periods [14]. The need for water reservation structure to store more water for use during dry seasons should be given priority.

During wet seasons, several season wetlands emerge beyond the Park boundaries, especially in the southern sections. There is always a tendency of most species spreading out governed by water availability and lush vegetation in the entire plain including the Park as documented by previous studies [43]. Wildebeest in particular spend the wet seasons outside the Park in the southern sections where the grass growth is more productive and rich in nutrients, and use the opportunity to breed before moving back to the Park. However, their movements back to the Park together with other plains 


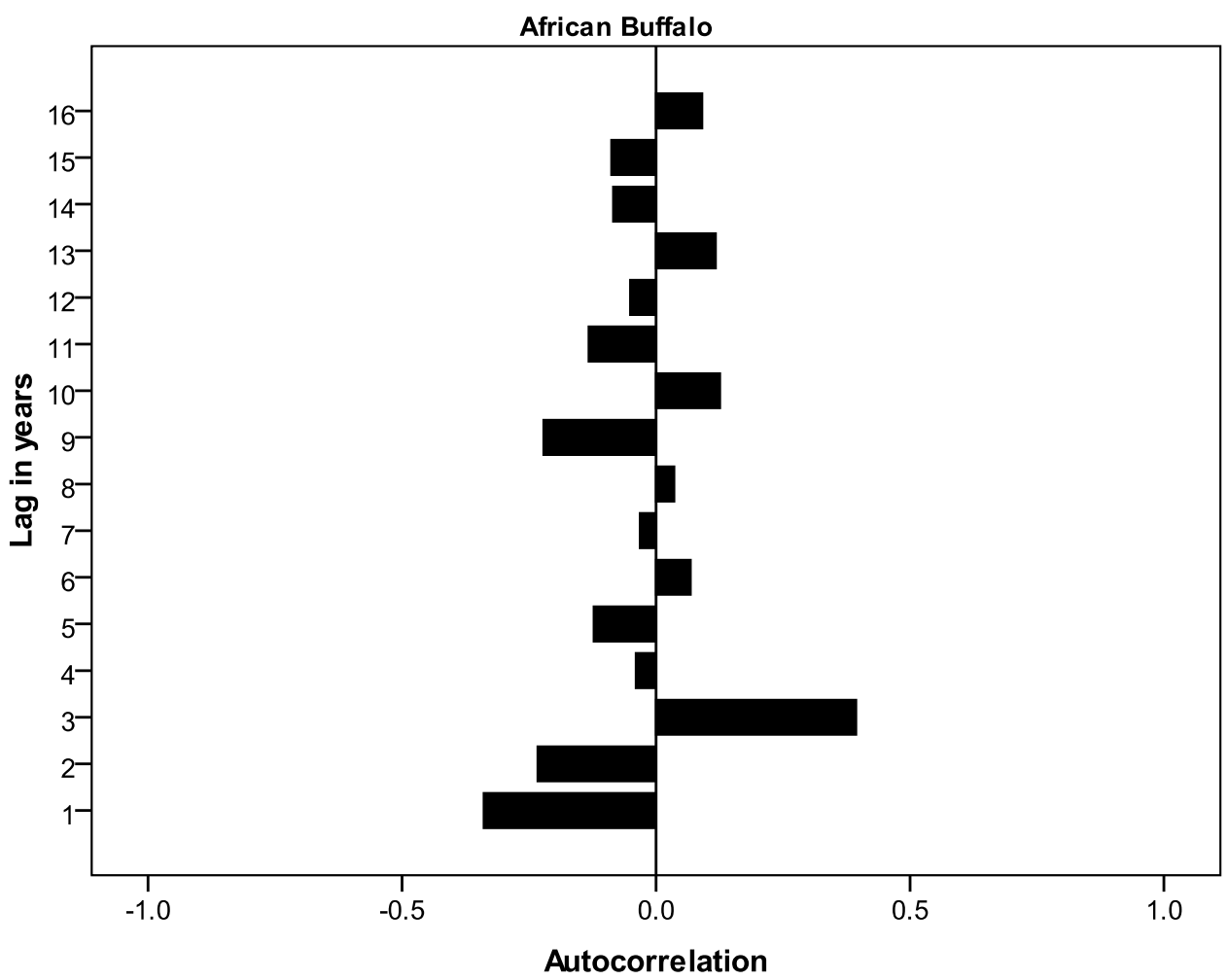

(a)

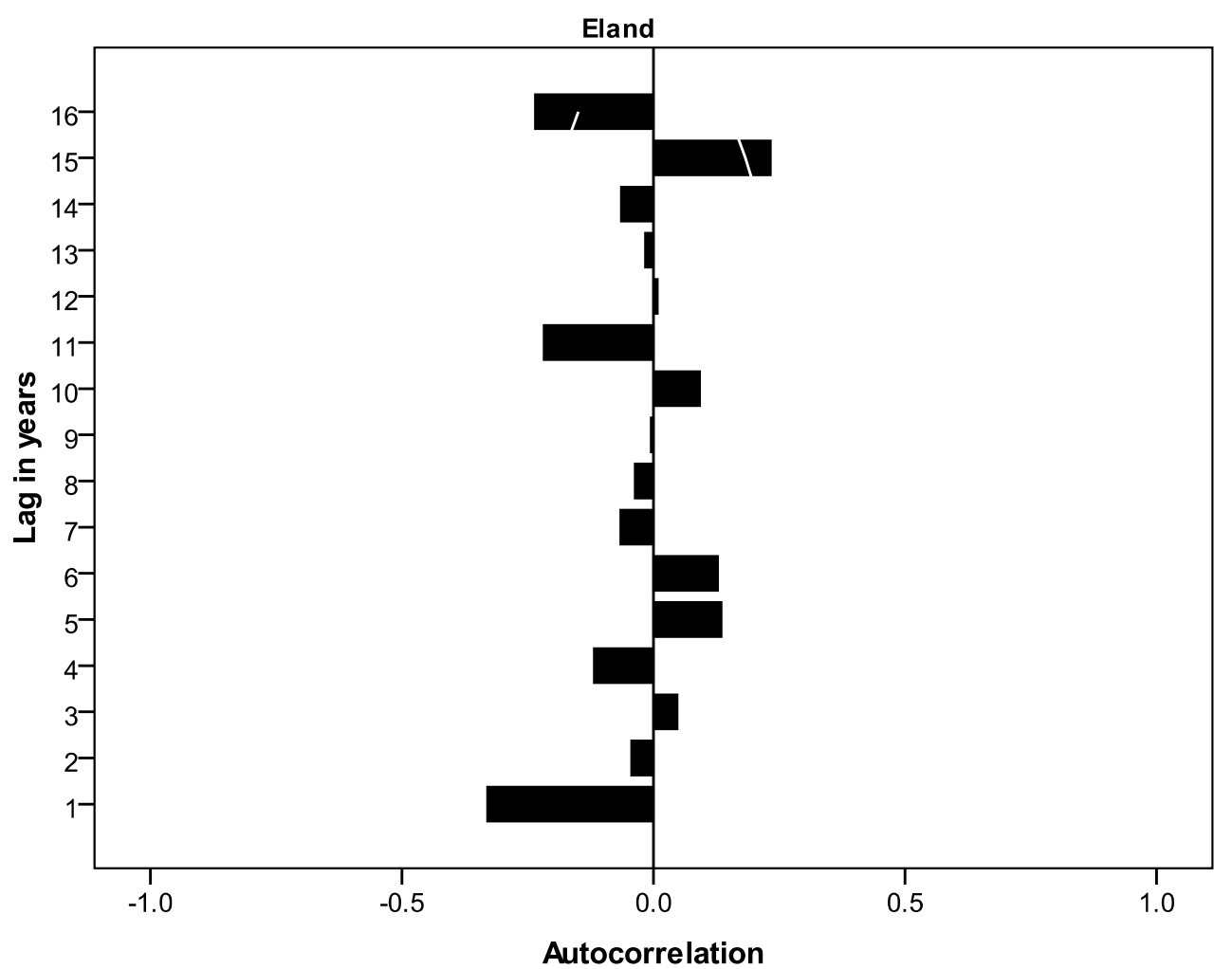

(b) 


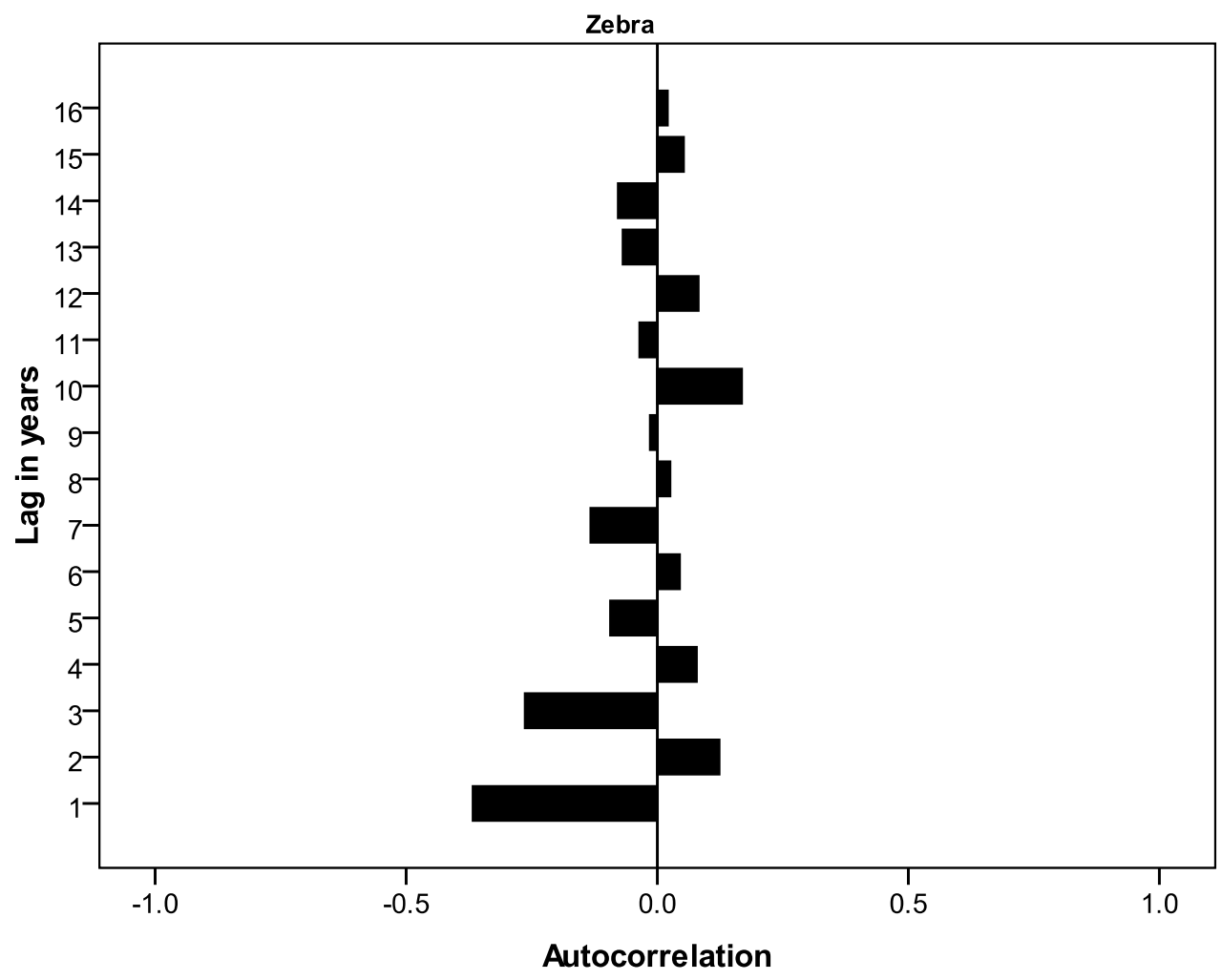

(c)

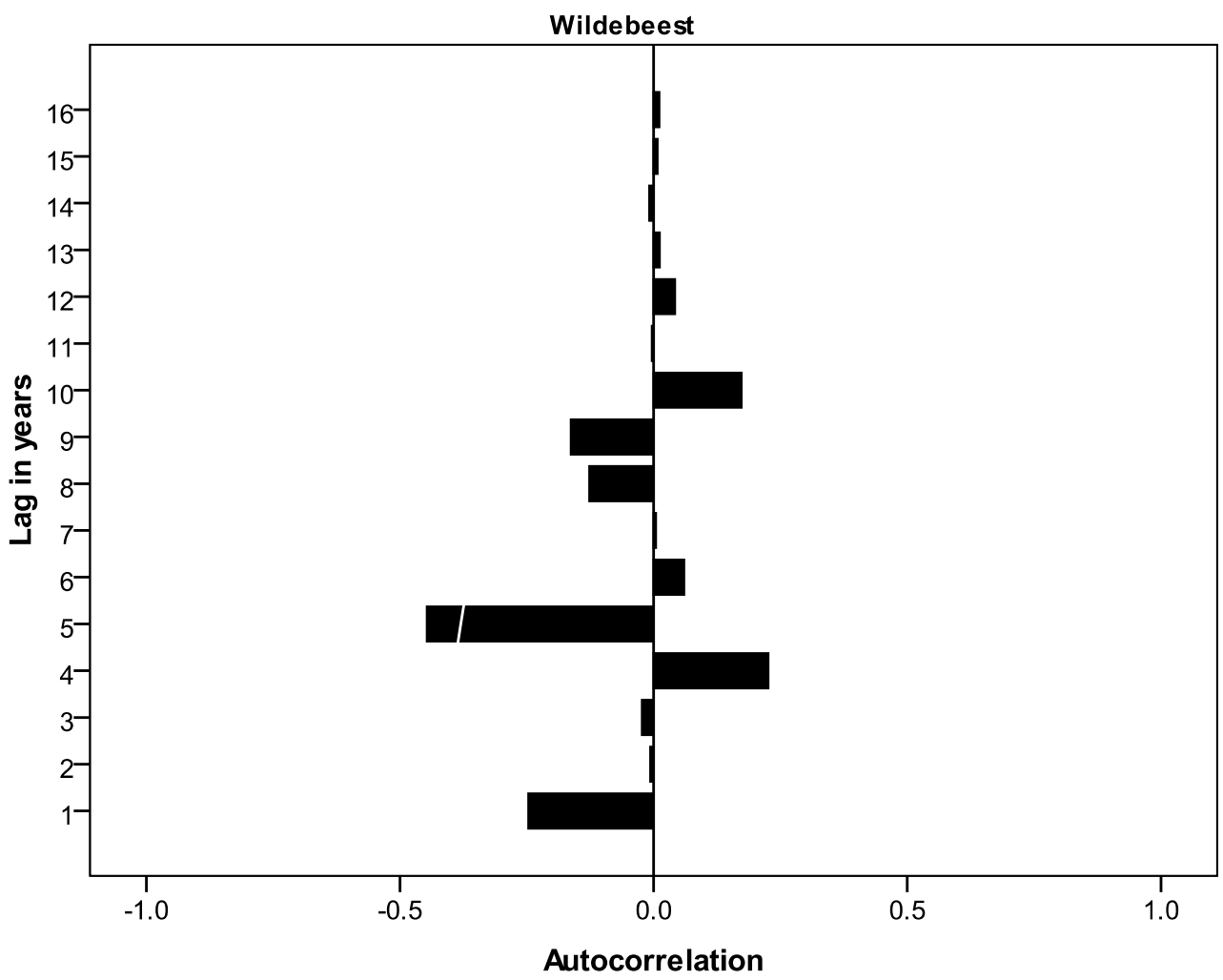

(d) 


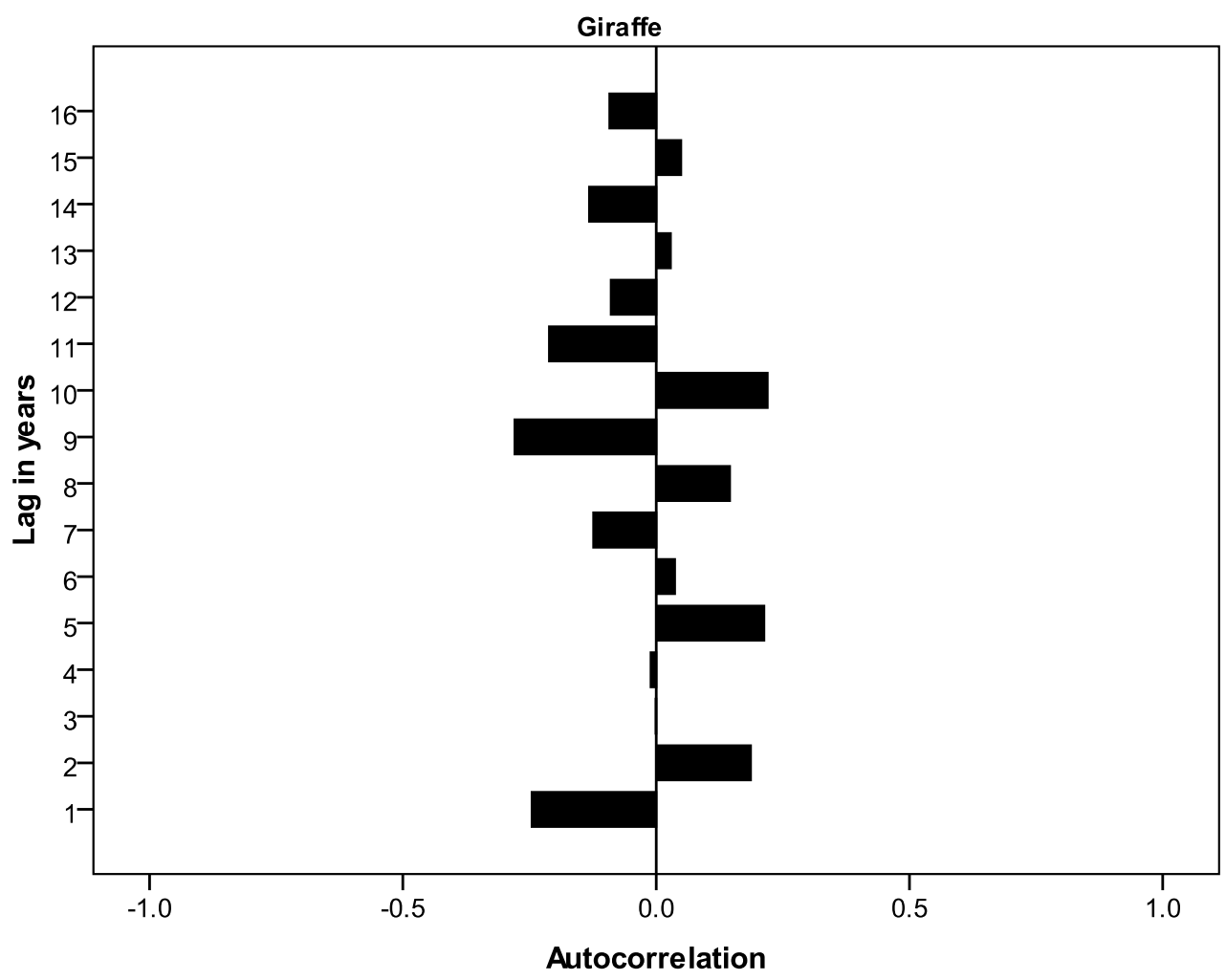

(e)

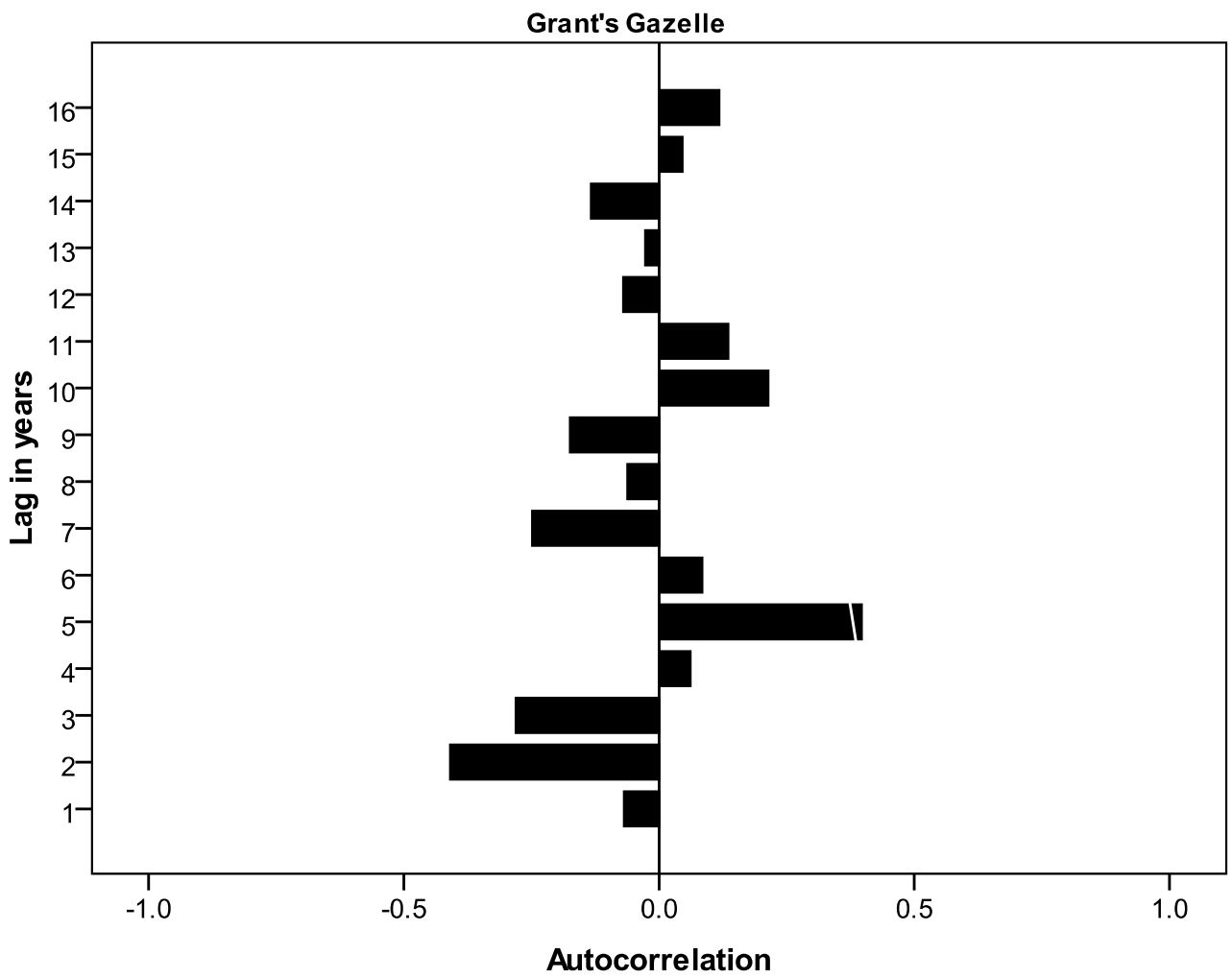

(f) 


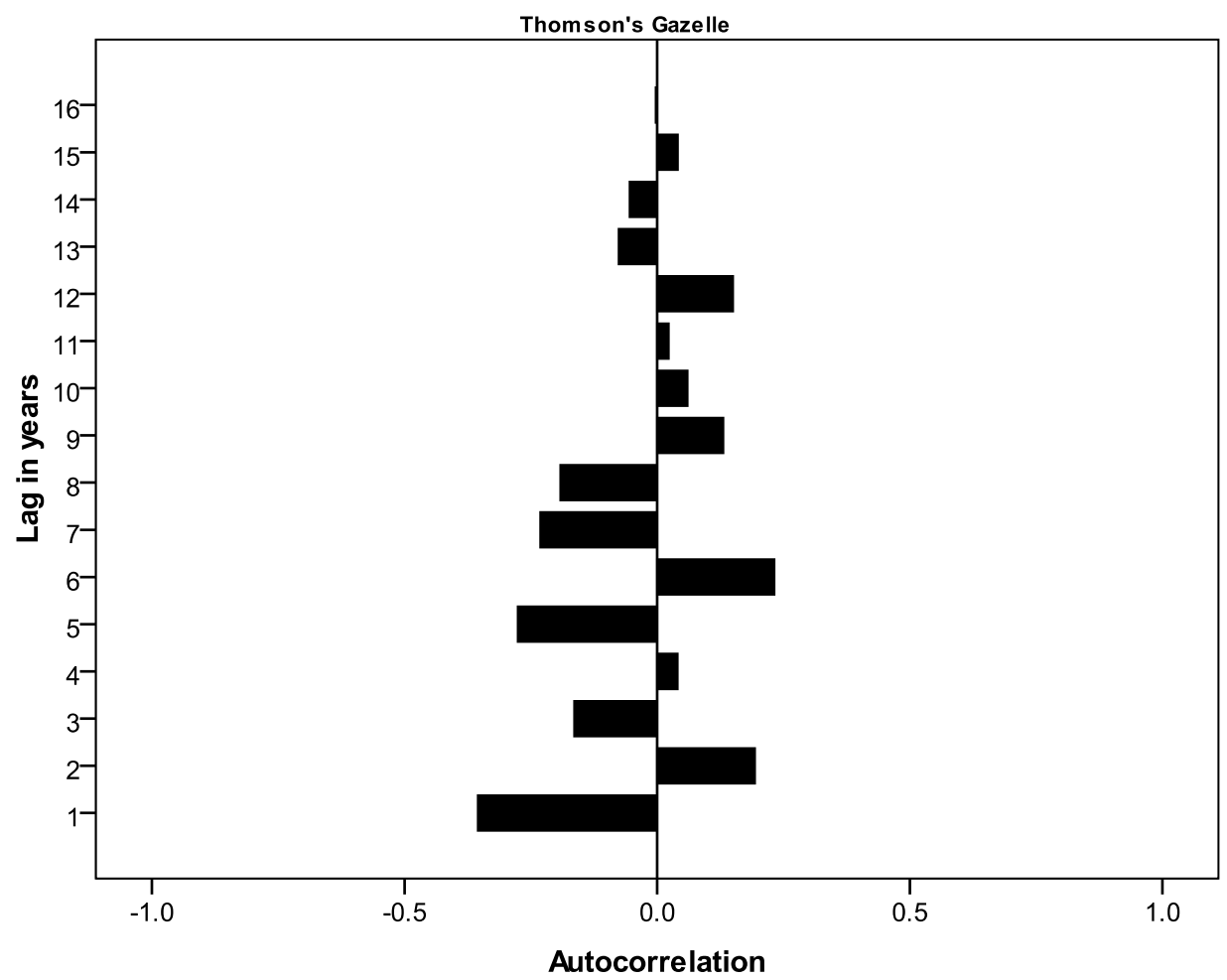

(g)

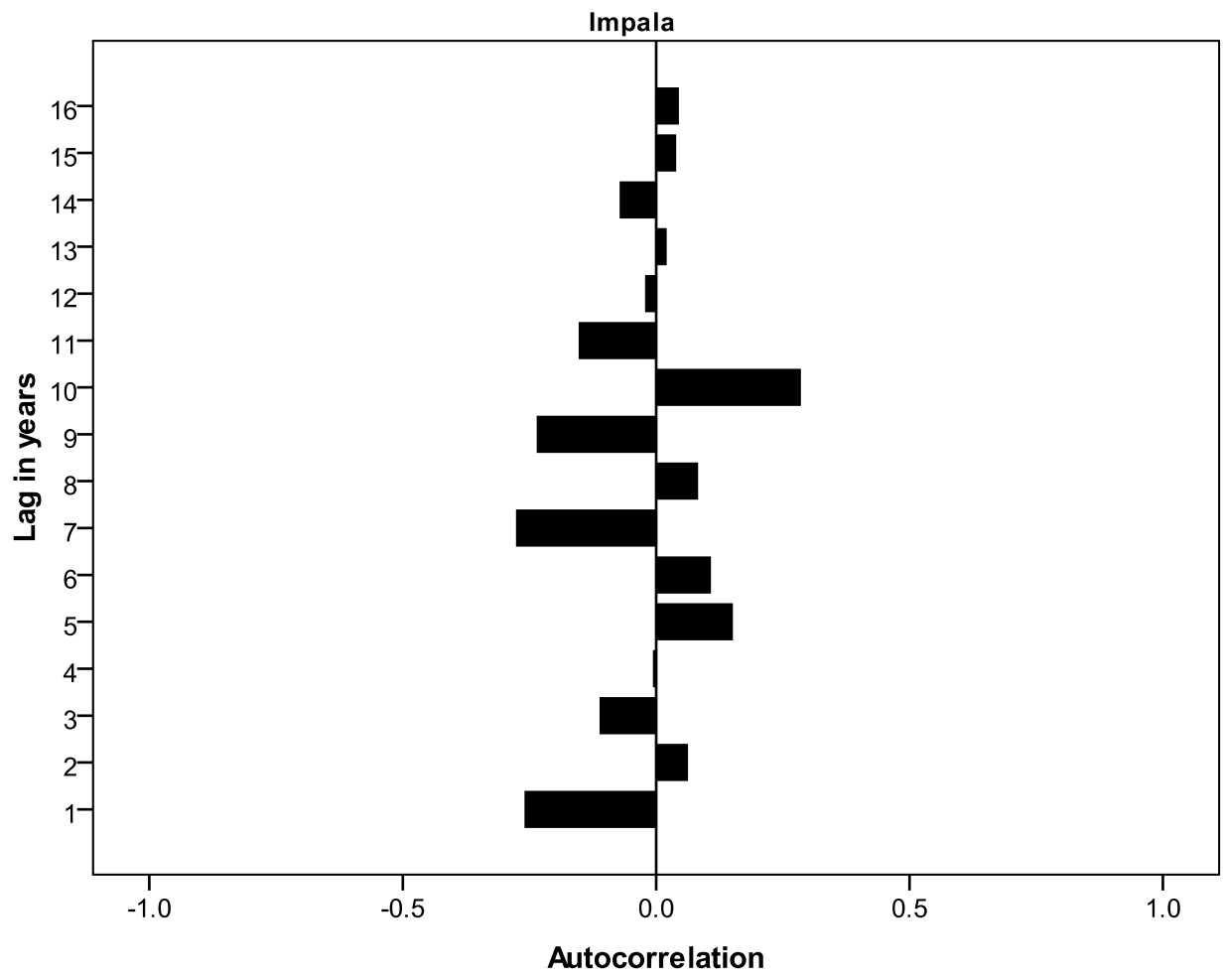

(h)

Figure 3. Autocorrelations with 95\% tolerance limits in numbers of eight herbivores ((a) African Buffalo's; (b) Eland; (c) Burchell's Zebra; (d) Wildebeest; (e) Giraffe; (f) Grant's Gazelle; (g) Thomson's Gazelle and (h) Impala) species at Nairobi National Park, 1990-2008. 
game appear to experiencing challenges due to diminishing space. This could explain their patterns as shown by autocorrelations after year 2000. Human settlements and livestock grazing within the dispersal area increased after the year 2000, and this has limited the movements of wildebeest and other plains game species to and from the Park.

\subsection{Reliability of Indication}

Wildlife species with similar ecology do show correlated patterns at specific sites, although not with complete consistency but the reliability of population estimates derived from censuses can be affected by counting errors and biases as animal numbers may be underestimated due to vegetation cover, especially for ground censuses $[35,44]$. However, our results still confirmed and extended patterns as documented from analysis of a subsection of the Kruger data [5].

From our analyses, it was further evident that patterns of variations for browsing species such as giraffes and elands were partly attributed to their ecology. These species feed mainly in browse, and fluctuations in their numbers within the Park were inter-correlated. These correlations make sense, but it is difficult to interpret the links between them, except in terms of overarching variables such as browse quality and availability. The observed correlation patterns for Burchell's Zebra with the abundances of other herbivores reaffirms the role of zebra in the vegetation succession within the Park. These ultimately influence abundance and distribution of other herbivores [45]. The repercussions resulting from indirect effects of rearrangement of wildlife communities and changes in the patterns of inter-specific interactions [45] will probably transform the character of wildlife species' interactions and fundamental ecosystem processes in unforeseen ways in the Park $[14,45]$.

Our analyses provide useful information for long-term herbivore populations' management at Nairobi National Park as they show long-term patterns of variations in numbers under a changing habitat condition. This would be important for the long-term conservation and management of wildlife in the Park. The continuation of monitoring of wildlife population through regular census would be essential as has been done over the past two decades. However, there is still need for collection of additional and complimentary information of biotic and abiotic information to allow for more focused analyses. Specific research topics linking wildlife population fluctuation patterns with the potential impacts of climate change and anthropogenic effects would be useful. In addition, land use planning and management of wildlife corridors and dispersal areas require considerable attention from all wildlife management stakeholders.

\section{Acknowledgements}

The wildlife census and monitoring programme is conducted as part of biodiversity monitoring and assessment by Kenya Wildlife Service for all conservation areas in the country. We thank Nairobi National Park management and volunteers who have over the years participated in these counts since the programme was initiated. We further thank anonymous reviewers who provided comments and suggestions on this manuscript.

\section{REFERENCES}

[1] C. Stoner, T. Caro, S. Mduma, C. Mlingwa, G. Sabuni, M. Borner and C. Schelten, "Changes in Large Herbivore Populations across Large Areas of Tanzania,” African Journal of Ecology, Vol. 45, No. 2, 2006, pp. 202-215. doi:10.1111/j.1365-2028.2006.00705.x

[2] J. M. Hellawell, "Development of a Rationale for Monitoring,” In: F. B. Goldsmith, Ed., Monitoring for Conservation and Ecology, Chapman \& Hall, London, 1991, pp. 1-14. doi:10.1007/978-94-011-3086-8_1

[3] N. C. Stenseth, "Population Cycles in Voles and Lemmings: Density Dependence in a Stochastic World," Oikos, Vol. 87, No. 3, 1999, pp. 427-461. doi:10.2307/3546809

[4] J. Fjeldsa, E. Lambin and B. Mertens, "Correlation between Endemism and Local Ecoclimatic Stability Documented by Comparing Andean Bird Distributions and Remotely Sensed Land Surface Data”, Ecography, Vol. 22, No. 1, 1999, pp. 63-78. doi:10.1111/j.1600-0587.1999.tb00455.x

[5] J. O. Ogutu and N. Owen-Smith, "Oscillations of Large Mammal Populations: Are They Related to Predation or Rainfall?” African Journal of Ecology, Vol. 43, No. 4, 2005, pp. 332-339. doi:10.1111/j.1365-2028.2005.00587.x

[6] J. O. Ogutu, H. P. Piepho, H. T. Dublin, N. Bhola and R. S. Reid, "Dynamics of Mara-Serengeti Ungulates in Relation to Land Use Changes,” Journal of Zoology, Vol. 278, No. 1, 2009, pp. 1-14. doi:10.1111/j.1469-7998.2008.00536.x

[7] J. O. Ogutu, N. Owen-Smith, H. P. Piepho and M. Y. Said, "Continuing Wildlife Population Declines and Range Contraction in the Mara Region of Kenya during 1977-2009,” Journal of Zoology, 2011, pp. 1-11.

[8] W. K., Ottichilo, J. De Leeuw, A. K. Skidmore, H. H. T. Prins and M. Y. Said, "Population Trends of Large Nonmigratory Wild Herbivores and Livestock in the Maasai Mara Ecosystem, Kenya, between 1977 and 1997," African Journal of Ecology, Vol. 38, No. 3, 2000, pp. 202-216. doi:10.1046/j.1365-2028.2000.00242.x

[9] B. M. Fitzgerald and J. A. Gibb, "Introduced Mammals in a New Zealand Forest: Long-Term Research in the Orongorongo Valley,” Biological Conservation, Vol. 99, No. 1, 2001, pp. 97-108. doi:10.1016/S0006-3207(00)00190-7

[10] N. Owen-Smith and M. G. L. Mills, "Manifold Interactive 
Influences on the Population Dynamics of a Multispecies Ungulate Assemblage,” Ecological Monographs, Vol. 76, No. 1, 2006, pp. 73-92. doi:10.1890/04-1101

[11] T. Caro and P. Scholte, "When Protection Falters," African Journal of Ecology, Vol. 45, No. 3, 2007, pp. 233235. doi:10.1111/j.1365-2028.2007.00814.x

[12] G. Harris, S. Thirgood, J. G. C. Hopcraft, J. P. G. M. Cromsigt and J. Berger, "Global Decline in Aggregated Migrations of Large Terrestrial Mammals," Endangered Species Research, Vol. 7, No. 1, 2009, pp. 55-76. doi:10.3354/esr00173

[13] D. Western, S. Russell and I. Cuthill, "The Status of Wildlife in Protected Areas Compared to Non-protected Areas of Kenya” PLoS ONE, Vol. 4, No. 7, 2009, e6140. doi:10.1371/journal.pone.0006140

[14] J. O. Ogutu, H. P. Piepho, H. T. Dublin, N. Bhola and R. S. Reid, "El Nino-Southern Oscillation, Rainfall, Temperature and Normalized Difference Vegetation Index fluctuations in the Mara-Serengeti Ecosystem," African Journal of Ecology, Vol. 46, No. 2, 2007, pp. 132-143. doi:10.1111/j.1365-2028.2007.00821.x

[15] J. O. Ogutu, H. P. Piepho, H. T. Dublin, N. Bhola and R. S. Reid, "Rainfall Influences on Ungulate Population Abundance in the Mara-Serengeti Ecosystem," Journal of Animal Ecology, Vol. 77, No. 4, 2008, pp 814-829. doi:10.1111/j.1365-2656.2008.01392.x

[16] M. Thompson and K. Homewood, "Entrepreneurs, Elites and Exclusion in Maasailand: Trends in Wildlife Conservation and Pastoralist Development," Human Ecology, Vol. 30, No. 1, 2002, pp. 107-138. doi:10.1023/A:1014519113923

[17] M. Norton-Griffiths, M. Y. Said, S. Serneels, D. S. Kaelo, M. Coughenour, R. H. Lamprey, D. M. Thompson and R. S. Reid, "Land Use Economics in the Mara Area of the Serengeti Ecosystem,” In C. Packer and A. R. E. Sinclair, Eds., Serengeti III: Human Wildlife Interactions, University of Chicago Press, Chicago, 2009, pp. 379-416.

[18] M. Loibooki, H. Hofer, K. L. I. Cambpbell and M. L. East, "Bushmeat Hunting by Communities Adjacent to the Serengeti National Park, Tanzania: The Importance of Livestock Ownership and Alternative Sources of Protein and Income," Environmental Conservation, Vol. 29, No.3, 2002, pp. 391-398. doi:10.1017/S0376892902000279

[19] P. Turchin, "Complex Population Dynamics: A Theoretical/Empirical Synthesis,” Princeton University Press, Princeton, 2003.

[20] L. Jiang and N. Shao, "Autocorrelated Exogenous Factors and the Detection of Delayed Density Dependence," Ecology, Vol. 84, No. 8, 2003, pp. 2208-2213. doi:10.1890/02-0557

[21] H. H. T. Prins and H. Olff, "Species-Richness of African Grazer Assemblages: Towards a Functional Explanation,” In: D. M. Newbery, H. H. T. Prins and N. Brown, Eds., Dynamics of Tropical Communities, Blackwell Science Ltd., London, 1998.

[22] M. Okello, "An Assessment of the Large Mammal Component of the Proposed Wildlife Sanctuary Site in Maasi
Kuku Group Ranch near Amboseli, Kenya,” South African Journal of Wildlife Research, Vol. 35, No. 1, 2005, pp. 63-76.

[23] W. K. Ottichilo, J. de Leeuw and H. H. T. Prins, "Population Trends of Resident Wildebeest [Connochaetes Taurinus Hecki (Neumann)] and Factors Influencing Them in the Masai Mara Ecosystem, Kenya,” Biological Conservation, Vol. 97, No. 3, 2001, pp. 271-282. doi:10.1016/S0006-3207(00)00090-2

[24] P. Legendre and M. J. Fortin, "Spatial Pattern and Ecological Analysis,” Plant Ecology, Vol. 80, No. 2, 1989, pp. 107-138. doi:10.1007/BF00048036

[25] J. N. Perry, A. M. Liebhold, M. S. Rosenberg, J. Dungan, M. Miriti, A. Jakomulska and S. Citron-Pousty, "Illustrations and Guidelines for Selecting Statistical Methods for Quantifying Spatial Pattern in Ecological Data," Ecography, Vol. 25, No. 5, 2002, pp. 578-600. doi:10.1034/j.1600-0587.2002.250507.x

[26] A. M. Liebhold and J. Gurevitch "Integrating the Statistical Analysis of Spatial Data in Ecology,” Ecography, Vol. 25, No. 5, 2002, pp. 553-557. doi:10.1034/j.1600-0587.2002.250505.x

[27] M. D. Broten and M. Said, "Population Trends Of Ungulates in and Around Kenya's Maasai Mara Reserve,” In: A. R. E. Sinclair and P. Arcese, Eds., Serengeti II: Dynamics, Management and Conservation of an Ecosystem, University of Chicago Press, Chicago, 1995, pp. 169-193.

[28] J. O. Ogutu, "Herbivore Dynamics in the Mara Area of Kenya: The Influence of Land Use Change, Climate and Predators,” Shaker Verlag, Aachen, 2000.

[29] R. Lamprey and R. S. Reid, "Expansion of Human Settlement in Kenya's Maasai Mara: What Future for Pastoralism and Wildlife?” Journal of Biogeography, Vol. 31, No. 6, 2004, pp. 997-1032. doi:10.1111/j.1365-2699.2004.01062.x

[30] L. A. Bennun and P. Njoroge, "Important Bird Areas in Kenya," East Africa Natural History Society, Nairobi, 1999.

[31] R. E. McDowell, D. S. Sisler, C. Schermerhon, J. D. Reed and R. P. Bauer, "Game or Cattle for Meat Production on Kenyan Rangelands? Cornell International Agriculture Mimeo 101,” Cornell University, Ithaca, New York, 1983.

[32] H. W. Gichohi, "The Ecology of a Truncated Ecosystem- The Athi-Kaptei Plains,” PhD Thesis, University of Leicester, Leicester, 1996.

[33] H. W. Gichohi, "Direct Payments as a Mechanism for Conserving Important Wildlife Corridor Links between Nairobi National Park and Its Wider Ecosystem: The Wildlife Conservation Lease Programme," Proceedings of the 5th World Parks Congress, Durban, 8-17 September 2003.

[34] N. Odendaal, D. Shaw and A. Keding, "Results of the Namib Rand Nature Reserve Annual Game Count," Report of NamibRand Nature Reserve, Maltahöhe, 12 August 2007.

[35] A. O. Owino, J. O. Oyugi, O. O. Nasirwa and L. A. Ben- 
nun, "Patterns of Variation in Waterbird Numbers on Four Rift Valley Lakes in Kenya, 1991-1999,” Hydrobiologia, Vol. 458, 2001, pp.45-53. doi:10.1023/A:1013115724138

[36] T. J. Crawford, "The Calculation of Index Numbers from Wildlife Monitoring Data," In: F. B. Goldsmith, Ed., Monitoring for Conservation and Ecology, Chapman and Hall, London, 1991, pp. 225-248. doi:10.1007/978-94-011-3086-8_12

[37] M. J. Fortin, M. R. T. Dale and J. ver Hoef, "Spatial Analysis in Ecology," Encyclopedia of Environmetrics, Vol. 4, 2002, pp. 2051-2058.

[38] M. J. Fortin, R. Mark and T. Dale, "Spatial Analysis: A Guide for Ecologists," Cambridge University Press, Cambridge, 2005.

[39] P. C. Tobin, "Estimation of the Spatial Autocorrelation Function: Consequences of Sampling Dynamic Populations in Space and Time,” Ecography, Vol. 27, No. 6, 2004, pp. 765-775. doi:10.1111/j.0906-7590.2004.03977.x

[40] J. C. Hillman, "The Biology of Eland Taurotragus oryx Pallas in the Wild,” PhD. Thesis, University of Nairobi,
Nairobi, 1979.

[41] R. S., Reid, P. K. Thornton and R. L. Kruska, "Loss and Fragmentation of Habitat for Pastoral People and Wildlife in East Africa: Concept and Issues,” South African Journal of Grass and Forage Science, Vol. 21, 2004, pp. 171181.

[42] N. W. Sitati, "Human-Elephant Conflicts in the Maasai Mara Dispersal Areas of Transmara District,” PhD. Thesis, University of Kent, Kent, 2003.

[43] J. C. B. Peterson and R. L. Casebeer, "Distribution, Population Status and Group Composition of Wildebeest and Zebra on the Athi-Kaptei Plains,” Kenya Wildlife Management Project UNDP/FAO/KEN/71/526 Report No. 1, Nairobi, 1972.

[44] M. Norton-Griffiths, “Counting Animals. Handbook No.1,” African Wildlife Leadership Foundation, Nairobi, 1978 ,

[45] N. C. Stenseth, A. Mysterud, G. Ottersen, J. W. Hurrell, K. S. Chan and M. Lima, "Ecological Effects of Climate fluctuations,” Science, Vol. 297, No. 5585, 2002, pp. 1292-1296. doi:10.1126/science.1071281 